See Article page 17

\section{Commentary: Take-home messages regarding patients with coronavirus disease 2019 (COVID-19) and acute aortic syndromes}

\author{
Ourania Preventza, MD, ${ }^{\mathrm{a}, \mathrm{b}}$ and Dawn S. Hui, MD
}

The coronavirus disease 2019 (COVID-19) pandemic has placed significant strain on health care systems, physicians, and patients worldwide. At the beginning of the pandemic, reorganizing health care systems in different countries was a necessity, with focus on reserving intensive care resources for critically ill patients. ${ }^{1}$ Elective cardiac operations were postponed if it was deemed safe, ${ }^{1}$ with some governmental agencies providing guidance and frameworks for these decisions. $^{2}$

In this issue of the Journal, Lopez-Marco and colleagues ${ }^{3}$ summarize the treatment of acute aortic syndromes in the United Kingdom during the initial months of the pandemic, when all elective surgical activity was placed on hold. In this study, all aortic surgery units in the United Kingdom were invited to participate, and $19(66 \%)$ accepted. The authors examined the impact that COVID-19 had at the beginning of the pandemic on patients in the United Kingdom with acute aortic syndromes regarding access to health care services. No COVID-19-related deaths were reported, although 7 patients were diagnosed postoperatively, and it is unclear whether they had subclinical disease during their operation or in the postoperative period. The authors concluded that despite the lack of universal guidelines at

From the a Division of Cardiothoracic Surgery, Michael E. DeBakey Department of Surgery, Baylor College of Medicine, Houston; 'bepartment of Cardiovascular Surgery, Texas Heart Institute, Houston; and ${ }^{\mathrm{c}}$ Department of Cardiothoracic Surgery, The Joe R. and Teresa Lozano Long School of Medicine, University of Texas Health Science Center at San Antonio, San Antonio, Tex.

Disclosures: The authors reported no conflicts of interest.

The Journal policy requires editors and reviewers to disclose conflicts of interest and to decline handling or reviewing manuscripts for which they may have a conflict of interest. The editors and reviewers of this article have no conflicts of interest.

Received for publication Dec 4, 2020; revisions received Dec 4, 2020; accepted for publication Dec 9, 2020; available ahead of print Jan 6, 2021.

Address for reprints: Ourania Preventza, MD, Division of Cardiothoracic Surgery, Michael E. DeBakey Department of Surgery, Baylor College of Medicine, One Baylor Plaza, BCM 390, Houston, TX 77030 (E-mail: preventz@bcm.edu).

JTCVS Open 2021;5:28-9

2666-2736

Copyright (c) 2020 The Authors. Published by Elsevier Inc. on behalf of The American Association for Thoracic Surgery. This is an open access article under the CC BY-NCND license (http://creativecommons.org/licenses/by-nc-nd/4.0/).

https://doi.org/10.1016/j.xjon.2020.12.003

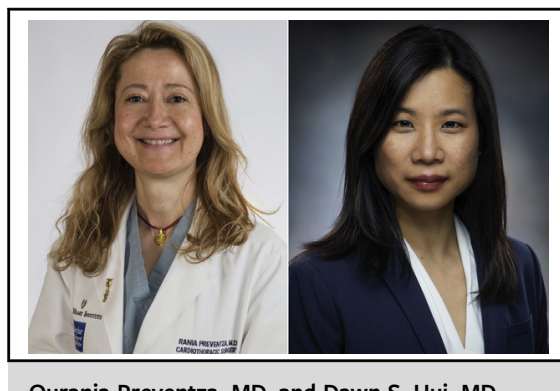

Ourania Preventza, MD, and Dawn S. Hui, MD

CENTRAL MESSAGE

Offering surgery to a patient with

acute type A aortic dissection is

life-saving, which makes asymp-

tomatic COVID-19 status of little

consequence aside from pro-

tecting health care personnel.

the beginning of the pandemic, acute aortic syndromes necessitating treatment were still treated as emergency cases, and the outcomes were no different before and during the pandemic.

The authors examined all acute aortic syndromes involving the ascending aorta, aortic arch, and descending and thoracoabdominal aorta. Modified protocols were used for patient selection, but it appears that no major modifications were made regarding patients with acute aortic pathology, who were categorized and treated as emergency patients as they were before the pandemic. Patients in the urgent category were treated 24 to 48 hours after presentation while they awaited COVID-19 testing results and noncontrast computed tomography. Presumably, patients in the urgent category, having survived the initial 24 to 48 hours without malperfusion or shock, were self-selected for better outcomes than emergency cases, which required immediate intervention. ${ }^{4,5}$

Although some of the points that the authors make are health care system-specific, and it unclear how generalizable and pertinent these data are to other health care systems, there are some important take-home messages. The authors elegantly describe intubation protocols set by the cardiac anesthesiologists to minimize the spread of COVID-19. These protocols include a 20-minute waiting period after intubation, during which no operating room staff except the anesthesiologists can enter the operating room, and the operating staff's mandate to remain in the 
operating room until the end of the procedure. Over time, such protocols have been adopted by other hospitals and countries caring for patients with COVID-19.

Another interesting observation, similar to other surgeons' perceptions, was the paucity of patients who presented with acute aortic syndromes at the beginning of the pandemic, which perhaps was a reflection of patients' anxiety about going to the emergency department at that time. In a recent report from Bologna, ${ }^{6}$ which describes results similar to those in this report, ${ }^{3}$ a high incidence of more complicated type A aortic dissection was noted during the pandemic. Patients more often presented in extremis, and, as a result, their treatment got delayed and became more complicated. ${ }^{6}$ A similar phenomenon wherein patients delay seeking care has been seen with acute coronary syndrome, with patients with ST-elevation myocardial infarction presenting later in their disease course. ${ }^{7-9}$ In addition, while shortage of blood products was a concern initially in the surgical treatment of aortic syndromes, the cancellation of elective cases resulted in blood bank reserves being maintained in this study. ${ }^{3}$ It is true that most, if not all, tertiary centers around the world will not deny surgery to a patient with acute type A aortic dissection. Thus, outside of symptomatic cases, COVID-19 status is of little consequence aside from the need to protect health care personnel.

Finally, we wish to commend the authors and the participating centers. It is admirable that a multicenter study answering an important clinical question could be conducted in the midst of an ongoing health care crisis. Understandably, several centers could not participate because of lack of resources. While this study provides insight into the early phase of the pandemic, evolving circumstances and rates of exposure will necessitate future studies and an ongoing commitment to scientific investigation to inform our practices in a pandemic that continues to surge.

The authors thank Stephen N. Palmer, PhD, ELS, of the Department of Scientific Publications at the Texas Heart Institute, for providing editorial support.

\section{References}

1. Gaudino M, Chikwe J, Hameed I, Robinson NB, Fremes SE, Ruel M. Response of cardiac surgery units to COVID-19: an internationally-based quantitative survey. Circulation. 2020;142:300-2.

2. Centers for Medicare \& Medicaid Services. CMS adult elective surgery and procedures recommendations: limit all non-essential planned surgeries and procedures, including dental, until further notice. Available at: https://www. $\mathrm{cms}$.gov/files/document/covid-elective-surgery-recommendations.pdf. Accessed December 4, 2020.

3. Lopez-Marco A, Rosser B, Harky A, Verdichizzo D, McPherson I, Hope E, et al The fate of patients with acute aortic syndrome during the coronavirus (COVID-19) pandemic: a UK multicenter study. J Thorac Cardiovasc Surg Open. 2021;5:17-25.

4. Preventza O, Coselli JS. Type A aortic dissection in self-selected patients: what seems to fit a few does not fit all. J Thorac Cardiovasc Surg. 2016;151:1593-4.

5. Scholl FG, Coady MA, Davies R, Rizzo JA, Hammond GL, Kopf GS, et al. Interval or permanent nonoperative management of acute type A aortic dissection. Arch Surg. 1999; 134:402-5; discussion 5-6.

6. Murana G, Folesani G, Botta L, Di Marco L, Leone A, Loforte A, et al. The effect of COVID-19 lockdown on acute type A aortic dissection: insights from Bologna. J Thorac Cardiovasc Surg Tech. 2020;4:50-4.

7. Gramegna M, Baldetti L, Beneduce A, Pannone L, Falasconi G, Calvo F, et al. ST segment-elevation myocardial infarction during COVID-19 pandemic: insights from a regional public service healthcare hub. Circ Cardiovasc Interv. 2020;13: e009413.

8. Tam CF, Cheung KS, Lam S, Wong A, Yung A, Sze M, et al. Impact of coronavirus disease 2019 (COVID-19) outbreak on ST-segment-elevation myocardial infarction care in Hong Kong, China. Circ Cardiovasc Qual Outcomes. 2020;13: e006631.

9. Wilson SJ, Connolly MJ, Elghamry Z, Cosgrove C, Firoozi S, Lim P, et al Effect of the COVID-19 pandemic on ST-segment-elevation myocardial infarction presentations and in-hospital outcomes. Circ Cardiovasc Interv. 2020;13:e009438. 